\title{
Effect of Solvents on Bioconversion of Penicillin G to Deacetoxycephalosporin G
}

\author{
QIANG GaO ${ }^{\dagger}$ and ARnold L. Demain* \\ Biology Department, Massachusetts Institute of Technology, \\ Cambridge, MA 02139, U.S.A.
}

(Received for publication June 25, 2001)

\begin{abstract}
The bioconversion of penicillin $\mathrm{G}$, an inexpensive substrate, to the valuable intermediate for semisynthetic cephalosporin production, deacetoxycephalosporin G (DAOG), had been recently shown to be increased by eliminating agitation and adding decane. The present work examining other solvents shows that all alkanes tested are equivalent to decane in activity but that other solvents are either inhibitory or less active than alkanes. Optimum conditions of $\mathrm{pH}$ and temperature for the alkane system are not very different from the previously used aqueous system.
\end{abstract}

The current method of producing cephalosporin intermediates from penicillins for synthesis of semisynthetic cephalosporins is a chemical process ${ }^{1)}$ which involves many steps, is expensive and generates polluting materials. We are attempting to develop an environmentally-friendly biological process for expanding the thiazolidine ring of penicillin $\mathrm{G}$ into the dihydrothiazine ring of deacetoxycephalosporin $\mathrm{G}(\mathrm{DAOG})^{2 \sim 5)}$. DAOG can be easily converted enzymatically into 7aminodeacetoxycephalosporanic acid (7-ADCA), an important feed stock for production of many semisynthetic cephalosporins. Semisynthetic cephalosporins are the leading group of antibiotics with a total market of 11 billion dollars per year ${ }^{6)}$.

Unfortunately, the degree of conversion of penicillin G into DAOG is very low due to the inactivation of the deacetoxycephalosporin C synthetase (DAOCS; expandase) during the bioconversion by the cofactors of the reaction, i.e., $\mathrm{Fe}^{2+}$ plus $\alpha$-ketoglutarate or plus ascorbate ${ }^{7)}$. We have been exploring means of retarding the inactivation and have recently found that elimination of agitation and addition of decane stimulates the degree of conversion ${ }^{8)}$.

Our rationale for testing decane was the knowledge that water-immiscible solvents are usually less toxic to cells than water-miscible solvents, often increase enzyme activity and stability and prevent the hydrolysis of the substrate or product ${ }^{9 \sim 11}$. Since they are also known to decrease toxicity of the substrate and/or product, we thought that they might also decrease the inactivation of the expandase by $\mathrm{Fe}^{2+}$ plus ascorbate or $\mathrm{Fe}^{2+}$ plus $\alpha$-ketoglutarate. We favored the alkanes because they are relatively biocompatable, having $\log \mathrm{P}$ (octanol-water partition coefficient) values over 3.0. $\log \mathrm{P}$ values for some alkanes are as follows: cyclohexane 3.2, hexane 3.5, heptane 4.0 , octane 4.5 , hexadecane 8.7 . Such high $\log P$ values are favorable for activity and stability of cells and enzymes $^{12)}$. When compared to other solvents for enzyme catalyzed reactions, alkanes are often best ${ }^{13 \sim 15)}$. Decane was tested first because it had been reported to have minimum deleterious effects on microbial viability ${ }^{16)}$. The present work examines other solvents including a number of additional alkanes.

\section{Materials and Methods}

\section{Microorganism, Medium and Culture Conditions}

The microorganism used was $S$. clavuligerus NP1, a mutant strain that produces only a trace of cephamycins ${ }^{17}$. It is useful since it does not carry over detectable cephalosporins into the bioconversion reaction. Inocula were obtained by growth in $250 \mathrm{ml}$ baffled Erlenmeyer flasks containing $40 \mathrm{ml}$ of MST medium ${ }^{2)}$ for 48 hours at $30^{\circ} \mathrm{C}$ and $220 \mathrm{rpm}$. Four $\mathrm{ml}$ of this seed were transferred

\footnotetext{
* Corresponding author: ademain@drew.edu

${ }^{\dagger}$ Present address: Department of Chemical Engineering, University of Colorado, Boulder, CO 80309-0424
} 
Fig. 1. DAOG production in the presence of $32 \%$ $(\mathrm{v} / \mathrm{v})$ concentrations of decane $(O)$, hexane $(\mathrm{O})$, benzene (A), butanol (ם) and DMSO (ם).

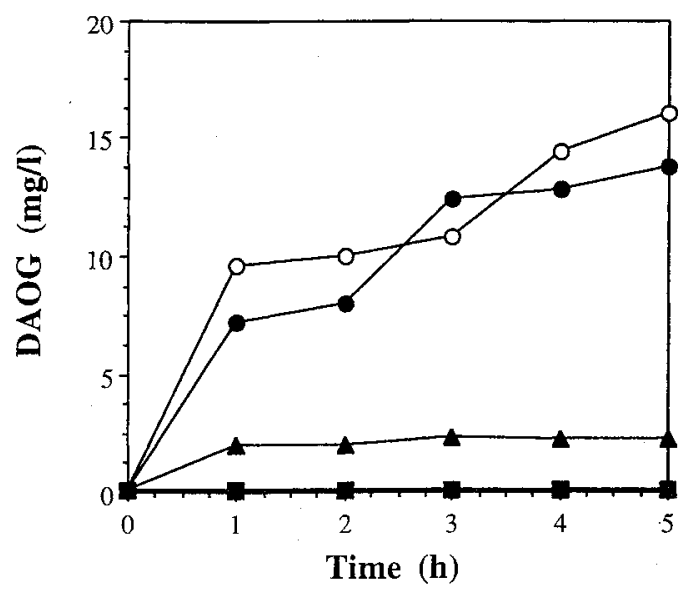

into each of a number of $500 \mathrm{ml}$ baffled flasks containing $80 \mathrm{ml}$ of MT2E medium ${ }^{3)}$ containing 3\% Trypticase Soy Broth without Dextrose (BBL Cockeysville, MD), 2\% ethanol and $90 \mathrm{~mm}$ MOPS buffer. The ethanol was added just before inoculation. The $\mathrm{pH}$ of the rest of the medium was adjusted to 7.0 before autoclaving. Cells were grown at $30^{\circ} \mathrm{C}$ at $250 \mathrm{rpm}$ for 24 hours. Mycelia were pooled, washed twice and finally resuspended into $10 \mathrm{ml}$ of distilled water per original flask. Four $\mathrm{ml}$ of the cell suspension were used in each ring-expanding biocoversion. The rest of the suspension was stored at $-20^{\circ} \mathrm{C}$ up to 4 weeks for later use in the biocoversion reaction.

\section{Ring-expanding Bioconversion}

The control biotransformation mixture contained $1.8 \mathrm{~mm}$ $\mathrm{FeSO}_{4}, 1.28 \mathrm{mM} \alpha$-ketoglutarate, $4 \mathrm{mM}$ ascorbate, $8 \mathrm{~mm}$ $\mathrm{MgSO}_{4} \cdot 7 \mathrm{H}_{2} \mathrm{O}, 8 \mathrm{mM} \mathrm{KCl}, 5.6 \mathrm{~mm}$ penicillin $\mathrm{G}(2 \mathrm{mg} / \mathrm{ml})$, 3.2 or $5 \mathrm{ml}$ decane and $50 \mathrm{~mm}$ MOPS (pH 6.5) in a final volume made up to $10 \mathrm{ml}$ with distilled water in $250 \mathrm{ml}$ baffled Erlenmeyer flasks. The $\mathrm{pH}$ was adjusted to 6.5 with $\mathrm{KOH}$. The order of addition of components was as established earlier ${ }^{18)}$. Incubation was static ${ }^{8)}$ at $30^{\circ} \mathrm{C}$. Samples were collected at zero time and at hourly intervals up to 5 hours. Reactions were stopped by mixing $0.5 \mathrm{ml}$ of the reaction mixture with $0.5 \mathrm{ml}$ methanol, and centrifuging to remove cells. Product (DAOG) concentration was determined on the supernatants with the paper discagar diffusion bioassay using Escherichia coli strain Ess ( $\beta$-lactam supersensitive mutant) with $50,000 \mathrm{IU}$ of
Fig. 2. Stimulation of DAOG production by $32 \%$ concentrations of decane $(\square)$, octane (ब), dodecane $(\mathrm{O})$ and hexadecane $(\boldsymbol{\square})$.

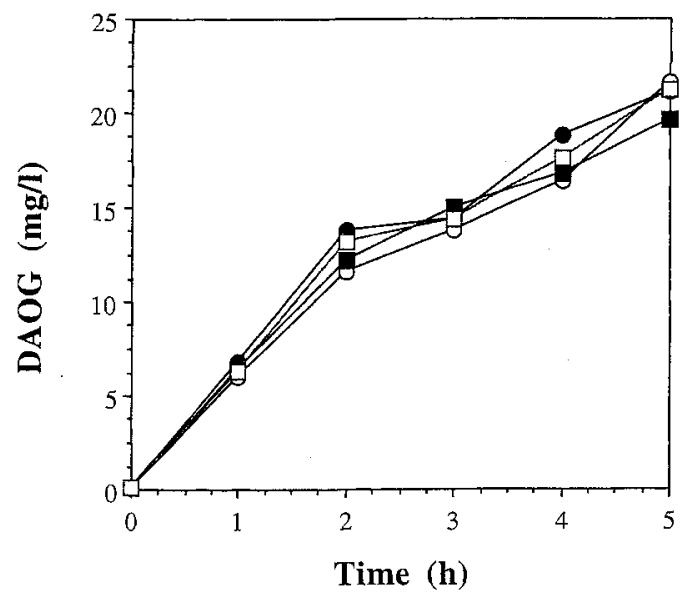

penicillinase (Difco Bactopenase concentrate) per $\mathrm{ml}$ of LB agar $^{2}$. DAOG was used as standard. The DAOG was made up in $32 \%$ or $50 \%$ decane, depending on the concentration in the reaction mixture. The addition of decane to standard DAOG was done since the zone diameter produced by DAOG was slightly enhanced by decane.

\section{Results}

The positive effects of eliminating agitation during the reaction and adding 32\% decane were found in our previous study ${ }^{8}$. A series of other solvents were compared to decane at the $32 \%$ concentration. It was found that the reaction was totally inhibited by $n$-butanol, DMSO, dioxane, isopropyl alcohol and cyclohexanol, and almost completely by benzene. Some of these data are shown in Fig. 1. Solvents that were as effective as decane were hexane (Fig. 1), heptane, octane, dodecane and hexadecane (Fig. 2). Solvents that were active but less active than the above alkanes were $p$-xylene, butylacetate, and octanol-1 (data not shown). The conversion was only slightly improved by increasing the alkane concentration up to $53 \%$ concentration (data not shown).

We decided to recheck other conditions of the alkanestimulated bioconversion. For this work, 50\% hexane was used. Variation in $\mathrm{pH}$ from 5.5 to 8.5 showed that the reaction was totally inhibited at $\mathrm{pH} 8.5$, seriously inhibited by $\mathrm{pH} 8.0$ and slightly inhibited at $\mathrm{pH} 7.5$ (data not shown). 
Fig. 3. Effect of temperature on DAOG production in the presence of $50 \%$ hexane.

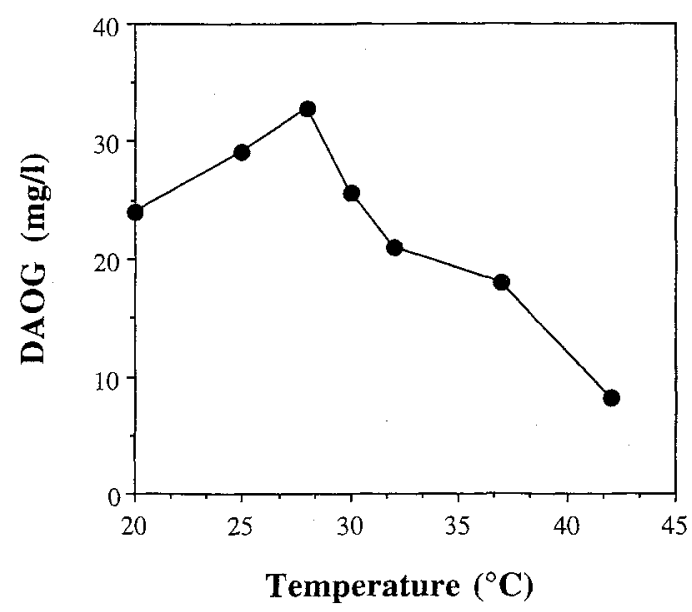

$\mathrm{pH} 5.5,6.0,6.5$ and 7.0 yielded equivalent activity indicating a plateau in bioconversion between $\mathrm{pH} 5.5$ and 7 .

Examination of temperature effects was done between $20^{\circ} \mathrm{C}$ and $42^{\circ} \mathrm{C}$ (Fig. 3). The reaction was seriously inhibited at $42^{\circ} \mathrm{C}$ and moderately inhibited at $37^{\circ} \mathrm{C}$. Fairly good conversions were observed at $20^{\circ} \mathrm{C}$ to $30^{\circ} \mathrm{C}$ with an optimum at $28^{\circ} \mathrm{C}$.

\section{Discussion}

Applications of enzymes and cells have been broadened by the use of organic solvents replacing part or all of the water in a reaction mixture ${ }^{19)}$. Reactions that do not occur in water can be catalyzed, enzymes can be made more stable, they can exhibit "molecular memory", and can experience changes in selectivity including substrate-, stereo-, regio- and chemo-selectivity. Stability enhancement was the reason that we first tested organic solvents and found success with decane ${ }^{8}$. In the present study, the stimulation of the bioconversion of penicillin $G$ to DAOG was observed with all alkanes tested. i.e. hexane, heptane, octane, decane, dodecane and hexadecane. No other solvents were as effective, with many having serious inhibitory effects. One possible reason for the alkane effect is the much higher solubility of oxygen in alkanes than in water. The alkane may act as an oxygen sponge, controlling the steady state level of oxygen in the aqueous medium. Thus, there could be a reduction of the oxygen concentration in the aqueous phase. Since oxygen is required for both the reaction and the inactivation of the expandase enmzyme, oxygen limitation might affect the inactivation more seriously than the bioconversion reaction. This would act in a manner similar to the beneficial effect of eliminating agitation of the reaction tubes ${ }^{8}$.

The optimum conditions in the alkane system was found to be a pH range of 5.5 to 7.0 and a temperature of $28^{\circ} \mathrm{C}$. Previously, we had used $\mathrm{pH} 6.5^{4)}$ and a temperature of $30^{\circ} \mathrm{C}^{2}$. Thus the alkane system, despite its greater activity, does not have very different $\mathrm{pH}$ and temperature requirements that the completely aqueous system.

\section{Acknowledgments}

The work was supported by Antibioticos of Milan, Italy. Thanks are given to ERMANNO BERNASCONI for encouragement and to AIQI FANG for advice and assistance. The following companies are acknowledged for gifts used for general support of this laboratory: ADM, Fujisawa Pharmaceutical Co. Ltd., Kao Corporation, Meiji Seika Kaisha Ltd., Pfizer Inc., Schering-Plough Research Institute and Yamasa Corporation. We are indebted to Professor Alexander M. Klibanov of M. I. T. for his suggestion that the alkanes may act as oxygen sponges.

\section{References}

1) Chauvette, R. R.; P. A. Pennington, C. W. Ryan, R. D. C. CoOper, F. L. Jose, I. G. Wright, E. N. VAN Heyningen \& G. W. Huffman: Chemistry of cephalosporin antibiotics. 21. Conversion of penicillins to cephalosporins. J. Org. Chem. 36: 1259 1267, 1971

2) Cho, H.; J. L. Adrio, J. M. Luengo, S. Wolfe, S. Ocran, G. Hintermann, J. M. Piret \& A. L. Demain: Elucidation of conditions allowing conversion of penicillin $\mathrm{G}$ and other penicillins to deacetoxycephalosporins by resting cells and extracts of Streptomyces clavuligerus NP1. Proc. Natl. Acad. Sci. USA 95: $11544 \sim 11548,1998$

3) Fernandez, M.-J.; J. L. Adrio, J. M. Piret, S. Wolfe, S. Ro \& A. L. DEMAIN: Stimulatory effect of growth in the presence of alcohols on biotransformation of penicillin $\mathrm{G}$ into cephalosporin-type antibiotics by resting cells of Streptomyces clavuligerus NP1. Appl. Microbiol. Biotechnol. 52: 484 488, 1999

4) Baez-Vasquez, M. A.; J. L. Adrio, J. M. Piret \& A. L. DEMAIN: Further studies on the bioconversion of penicillin $G$ into deacetoxycephalosporin $G$ by resting cells of Streptomyces clavuligerus NP1. Appl. Biochem. Biotechnol. 81: 145 152, 1999

5) Demain, A. L. \& M. A. Baez-Vasquez: Immobilized Streptomyces clavuligerus NP1 cells for biotransformation of penicillin $\mathrm{G}$ into deacetoxycephalosporin G. Appl. Biochem. Biotechnol. 87: 135 140, 2000

6) Demarn, A. L.: Small bugs, big business: the economic power of the microbe. Biotechnol. Adv. 18: 499 514, 2000

7) Adrio, J. L.; H. Cho, J. M. Piret \& A. L. Demain: Inactivation of deacetoxycephalosporin $\mathrm{C}$ synthase 
in extracts of Streptomyces clavuligerus during bioconversion of penicillin $\mathrm{G}$ to deacetoxycephalosporin G. Enzyme Microb. Technol. 25: 497 501, 1999

8) GaO, Q. \& A. L. Demain: Improvement in the bioconversion of penicillin $\mathrm{G}$ to deacetoxycephalosporin $\mathrm{G}$ by elimination of agitation and addition of decane. Appl. Microbiol. Biotechnol., in press

9) Fukui, S. \& A. Tanaka: Enzymatic reactions in organic solvents. Endeavor, New Series, 9: 10 1, 1985

10) Nikolova, P. \& O. P. WARD: Whole cell biocatalysis in non-conventional media. J. Indust. Microbiol. 12: 76 86, 1993

11) Salter, G. J. \& D. B. Kell: Solvent selection for whole cell biotransformations in organic media. Crit. Rev. Biotech. 15: 139 177, 1995

12) D'Cunha, G. B.; V. Satyanarayan \& P. M. Nair: Novel direct synthesis of $L$-phenylalanine methyl ester by using Rhodotorula glutinis phenylalanine ammonia lyase in an organic aqueous biphasic system. Enzyme Microb. Technol. 16: 318 322, 1994

13) ZaKs, A. \& A. M. Kubanov: Enzyme-catalyzed processes in organic solvents. Proc. Nat. Acad. Sci. USA
82: $3192 \sim 3196,1985$

14) Dordick, J. S.: Enzymatic catalysis in monophasic organic solvents. Enzyme Microb. Technol. 11: 194 211,1989

15) GuO, Z.-W. \& C. J. Sit: Enzymatic synthesis of macrocyclic lactones. J. American Chem. Soc. 110: 1988 2001, 1999

16) Spinnler, H. E.; C. Ginies, J. A. Khan \& E. N. VULFSON: Analysis of metabolic pathways by the growth of cells in the presence of organic solvents. Proc. Natl. Acad. Sci. USA 93: 3373 3376, 1996 •

17) MaHro, B. \& A. L. Demain: In vivo conversion of penicillin $\mathrm{N}$ into a cephalosporin type antibiotic by a non-producing mutant of Streptomyces clavuligerus. Appl. Microb. Biotechnol. 27: 272 275, 1987

18) Shen, Y.-Q; S. Wolfe \& A. L. Demain: Desacetoxycephalosporin $\mathrm{C}$ synthetase: importance of order of cofactor/reactant addition. Enzyme Microb. Technol. 6: 402 404, 1984

19) Klibanov, A. M.: Improving enzymes by using them in organic solvents. Nature 409: $241 \sim 246,2001$ 